\title{
Perbandingan Efektifitas Metode Elektrokoagulasi dan Destilasi Terhadap Penurunan Beban Pencemar Fisik Pada Air Limbah Domestik
}

\author{
Muliyadi $^{*}$, Idayani Sangadji Sowohy ${ }^{1}$ \\ ${ }^{1}$ Environmental Health Department of Health Polytechnic of Ternate, Campus A Kota Ternate 97713, Indonesia, phone: \\ +6282233159448, fax: (0921) 3121870 \\ * Corresponding Author: muliyadi.blues90@gmail.com
}

Info Artikel : Diterima 13 Oktober 2019 ; Disetujui 2 Februari 2020 ; Publikasi 1 April 2020

\begin{abstract}
ABSTRAK
Latar belakang: Penghasil limbah cair terbesar di Indonesia umumnya berasal dari rumah tangga. Saat ini, dirasa perlu untuk mengembangkan metode penanganan limbah cair domestic ${ }^{(1)}$

Metode: Jenis ini merupakan penelitian eksperimental sederhana dengan rancangan post test only group control design. Penelitian ini dilakukan untuk mengetahui perbandingan efektifitas metode elektrokoagulasi dan destilasi dalam menurunkan beban pencemar fisik pada limbah cair domestic. Populasi dalam penelitian ini adalah seluruh limbah cair yang ada di parit perumahan dagymoi tubo. Sampel dalam penelitian ini adalah 10 liter limbah cair yang ada di parit perumahan dagymoi tubo . teknik pengambilan sampel menggunakan teknik purposive sampling.

Hasil: TDS pada perlakuan destilasi menurun sebesar 81,73\% (295 mg/l) sedangkan TDS pada elektrokoagulasi menurun sebesar 53,60\% (749 mg/ 1) dan TSS pada destilasi menurun sebesar 97,7\% (46 mg/l) dibandingkan TSS pada elektrokoagulasi menurun sebesar 74,69\%(505 mg/l).

Simpulan: Perlakuan dengan menggunakan destilasi lebih efektif dalam menurunkan kadar TDS dan TSS pada limbah cair domestic.
\end{abstract}

Kata kunci: Destilasi; Elektrokoagulasi; Total Dissolved Solid; Total Suspended Solid

\section{ABSTRACT}

Title: Comparison of the Effectiveness of Electrocoagulation and Distillation Methods in Reducing Physical Pollutant in Domestic Wastewater

Background: in general, the biggest producers of domestic wastewater in indonesia comes from household. Nowaday, the handling of domestic wastewater is needed to be improved. ${ }^{(1)}$

Methods: this type of research is a simple experimental study with a post test only group control design. This research was conducted to compare the effectiveness of the electrocoagulation and distillation methods in reducing physical pollutants in domestic wastewater. The population in this study is all of the wastewater in the dagymoi tubo residence trench. The sample in this study was 10 liters of wastewater in the dagymoi tubo residence trench. Sample taking technique using purposive sampling technique.

Results: TDS in distillation treatment decreased by $81.73 \%$ (295 $\mathrm{mg} / \mathrm{l}$ ) while TDS in electrocoagulation decreased by 53.60\% (749 $\mathrm{mg} / \mathrm{l}$ ) and TSS in distillation decreased by $97.7 \%$ (46 $\mathrm{mg} / \mathrm{l}$ ) compared to TSS in electrocoagulation decreased by $74.69 \%(505 \mathrm{mg} / \mathrm{l})$.

Conclusion: Treatment using distillation is more effective in reducing levels of TDS and TSS in domestic wastewater.

Keywords: Distillatio; Electrocoagulation; Total Dissolved Solid; Total Suspended Solid. 


\section{PENDAHULUAN}

Pencemaran lingkungan menjadi masalah yang sangat serius terutama di kota besar yang ada di Indonesia. Berbagai macam penyebab yang melatarbelakangi tejadinya pencemaran air, baik berasal dari pabrik maupun berasal dari fasilitas pelayanan kesehatan dimana pabrik dan fasilitas pelayanan kesehatan umumnya membuang limbah cair mereka langsung ke badan air. Akan tetapi, yang paling memegang peranan penting dalam pencemaran limbah cair baik disengaja maupun tidak berasal dari air buangan masyarakat yang jumlahnya setiap hari semakin meningkat. ${ }^{(2)}$

Pada umumnya dampak yang dirasakan tidak langsung berefek pada hari dimana limbah cair dibuang akan tetapi lebih kepada efek jangka Panjang. Efek jangka Panjang tersebut bisa menyebabkan penyakit pada manusia. Ada beberapa kasus dimana pencemaran air berdampak pada kesehatan manusia seperti kasus Minamata yang terjadi di teluk Minamata di jepang. Untuk di Indonesia kasus pencemaran limbah cair yang pernah terjadi adalah pencemaran di teluk buyat.. (3)

EHRA telah melakukan serangkain riset terkait indeks risiko air limbah domestic di kota ternate dengan area studi meliputi 4 kecamatan dengan hasil bahwa limbah cair perlu diperhatikan lebih serius hal ini dikarenakan cakupan tangka septik yang aman di wilayah teliti lebih dari $60 \%$, dengan cakupan pencemaran air karena pembuangan kotoran dari septik tank sekitar 21,4-65,9\%, terlebih lagi angka pencemaran akibat SPAL sangat tinggi yaitu $>50 \%$ kecuali pada strata 0 sebesar $12,5 \%$. Tentu saja hal ini akan berdampak negative bagi lingkungan perairan sekitas terutama sumber air bersih,. ${ }^{(4)}$

Di kota Ternate umumnya masyarakat membuang limbah langsung ke badan air tanpa melalui pengolahan terlebih dahulu. Adapun jika ada pengolahan hanya memanfaatkan sumur resapan atau tangka septik dengan memanfaatkan jasa pengangkutan lumpur tinja. Umumnya air limbah rumah tangga yang ada di kota Ternate tersalurkan melalui go dan parit yang ada disekitar rumah warga, hal ini tentunya dapat mencemari tanah dan badan air sehingga dapat berakibat buruk pada lingkungan. Hal ini sudah menjadi kebiasaan di kota Ternate dengan angka penggunaan septic tank sebesar $85,42 \%{ }^{(4)}$

Pemerintah kota Ternate sudah melakukan berbagai upaya dalam upaya pengolahan limbah cair diantaranya adalah pengadaan instalasi air limbah dengan dana Rp 478.380.000, Pembangunan MCK di kelurahan RUA dengan dana $\mathrm{Rp}$ 151.195.936, pembuatan septic tank komunal 3 unit di kelurahan mayau dengan dana sebesar Rp. 530.088.406, Pembuatan Septictank Komunal Kel. Lelewi sebanyak 3 unit dengan dana Rp. 530.088.406, Pembuatan Septictank Komunal Kel. Perum Bersatu sebanyak 3 unit dengan dana sebesar Rp. 363.075.604.(5) akan tetapi, peningkatan pencemaran air di maluku utara pada periode 2018 tercatat meningkay sebesar $370 \%$ dibandingkan pada periode sebelumnya. ${ }^{(6)}$

Berdasarkan hasil penelitian yang dilakukan oleh. ${ }^{(7)}$ menyatakan bahwa metode elektrokoagulasi dapat menurunkan total logam $\mathrm{Cr}$ total, BOD5, dan COD) yang ada pada limbah cair penyamakan kulit, hal ini telah memenuhi baku mutu SK Gubernur TK 1 Jawa Barat No. 6 Tahun 1999. Akan tetapi parameter TSS masih melebihi standar baku mutu yang disyaratkan. Sehingga dirasa perlu penambahan unit lain agar mampu mengurangi TDS sehingga memenuhi baku mutu yang telah disyaratkan. ${ }^{(7)}$

Penelitian mengenai efektifitas metode elektrokoagulasi dalam menurunkan beban pencemar pada air limbah domestik telah dilakukan oleh beberpa peneliti sebelumnya seperti pada penelitian..$^{(8)}$ yang mengemukakan bahwa Secara umum percobaan dengan metode elektrokoagulasi pada skala laboratorium pada kondisi batch, dirasa cukup efektif untuk menurunkan beban pencemar pada air limbah dengan pengurangan nilai COD sebesar $29,83 \%$ yang terjadi pada menit ke $20 .^{\left({ }^{(8)}\right.}$

Adapun penelitian yang dilakukan oleh. ${ }^{(9)}$ tentang destilasi air laut menggunakan pemanas matahari dengan reflektor cermin cekung menunjukkan bahwa sampel air sebelum dan sesudah destilasi menunjukkan peningkatan mutu kualitas yang sangat signifikan terutama dimana nilai salinitas menurun ke angka 0 yang sebelumnya mencapai 27,5 ppt.

Melihat dari sudut pandang dan beberapa penelitian yang meneliti mengenai pemanfaatan metode destilasi dan elektrokoagulasi sebagai teknologi tepat guna dalam pengolahan limbah cair maka perlu adanya suatu usaha untuk memanfaatkan metode alternatif berupa teknologi tepat guna, yaitu metode yang mampu dan mudah dikerjakan dari bahan yang umum dipakai dalam kehidupan seharihari untuk bisa diterapkan secara luas kepada seluruh lapisan masyarakat. Oleh sebab itu perlu dilakukan penelitian lebih lanjut terkait apakah metode elektrokoagulasi dan destilasi mampu menurunkan beban pencemar pada air limbah domestik

\section{MATERI DAN METODE}

Jenis penelitian ini merupakan penelitian eksperimental sederhana dengan rancangan post test only group control design.

Populasi dalam penelitian ini adalah seluruh limbah cair yang ada di parit perumahan dagymoi tubo. Sampel dalam penelitian ini adalah 10 liter limbah cair yang ada di parit perumahan dagymoi tubo dengan teknik pengambilan menggunakan teknik purposive sampling pemilihan sampel berdasarkan atas ciri-ciri atau sifat tertentu yang berkaitan dengan karakter populasi dari air limbah . Sifat tertentu yang dipakai pada penelitian ini adalah dipakainya sampel air limbah yang langsung dari saluran pembuangan warga agar didapatkan hasil yang representatif.. Pada penelitian ini akan dilakukan ujicoba menggunakan 
metode elektrokoagulasi untuk menurunkan beban pencemar kimia dengan mengalirkan listrik 12 volt selama 1 jam. Metode destilasi yang digunakan dalam penelitian ini merupakan destilasi sederhana dengan penguapan selama 30 menit dengan rancangan alat yang telah dibuat.

Jenis data dalam penelitian ini yaitu data primer dan data sekunder. Data primer pada penelitian ini adalah hasil pencatatan saat melakukan pengamatan di laboratorium. Data sekunder di peroleh dari literature, buku, serta data-data yang berhubungan dengan metode elektrokoagulasi dan destilasi baik berupa jurnal nasional maupun jurnal internasional.

Metode pengukuran TDS dan TSS menggunakan metode gravimetri di mana Gravimetri adalah salah satu metode analisis kuantitatif suatu zat atau komponen yang telah dikenal dengan mengukur berat komponen dalam keadaan murni setelah melalui proses pemisahan, metode gravimetri menekankan prinsip pemurnian dan penimbangan. Selain itu, analisis gravimetri dapat didefinisikan sebagai proses isolasi dan pengukuran berat unsur atau senyawa tertentu. Bagian terbesar dari analisis gravimetri melibatkan transformasi unsur radikal menjadi senyawa stabil murni.SNI 2019

\section{Perhitungan TDS}

$\mathrm{TDS}=1000 / \mathrm{V} \times(\mathrm{F}-\mathrm{B}) \times 1000=\ldots \mathrm{mg} / \mathrm{L}$

Informasi

$\mathrm{B}=$ berat cawan penguap $(\mathrm{g})$

$\mathrm{F}=$ berat cawan penguap + residu terlarut $(\mathrm{g})$

Perhitungan TSS

$\mathrm{TSS}=1000 / \mathrm{V} \times\{\mathrm{G} \times(\mathrm{C}+\mathrm{D})\} \times 1000=\ldots \mathrm{mg} / \mathrm{L}$

Informasi

$\mathrm{C}=$ berat cawan penguap $(\mathrm{g})$

$\mathrm{D}=$ Filter Berat kertas $(\mathrm{g})$

$\mathrm{G}=$ berat cawan penguap + filter kertas filter $(\mathrm{g})$

\section{HASIL DAN PEMBAHASAN}

Tabel 1. Perbandingan Nilai TDS dan TSS sebelum dan setelah elektrokoagulasi dan destilasi

\begin{tabular}{ccccccc}
\hline & \multicolumn{9}{c}{ Perbandingan } \\
Sebelum & \multicolumn{2}{c}{ Sesudah Elektrokoagulasi } & \multicolumn{2}{c}{ Sesudah Destilasi } \\
\hline Parameter & Hasil & Satuan & Hasil & satuan & Hasil & satuan \\
TDS & 1614 & $\mathrm{mg} / 1$ & 749 & $\mathrm{mg} / \mathrm{l}$ & 295 & $\mathrm{mg} / 1$ \\
TSS & 1995 & $\mathrm{mg} / \mathrm{l}$ & 505 & $\mathrm{mg} / 1$ & 46 & $\mathrm{mg} / 1$ \\
\hline
\end{tabular}

Dari table diatas menunjukkan bahwa TDS dan TSS pada limbah cair domestic di perumahan Tubo telah melewati baku mutu yang telah ditetapkan oleh permenlh no 1 tahun 2010 dimana nilai TDS 1614 $\mathrm{mg} / \mathrm{l}$ dan TSS $1995 \mathrm{mg} / \mathrm{l}$. Jika tidak ada pengolahan terus menerus akan mengakibatkan penumpukan dan pengapungan pada padatan terlarut maupun padatan yang terendapkan, tentu saja hal ini dapat berefek pada kesehatan baik lingkungan maupun manusia hal ini seperti yang tertulis pada jurnal . (10) yang menyatakan bahwa TDS umumnya mengandung zatzat organic yang memilki diameter sebesar $<10-3 \mu \mathrm{m}$. Pada umumnya ion yang paling banyak pada limbah cair adalah kalsium, fosfat, nitrat, natrium, kalium, magnesium, bikarbonat, karbonat dan klorida. Adapun Bahan kimia yang paling sering ada dalam limbah cair seperti kation, anion, molekul atau aglomerasi dari ribuan molekul. Pada dasarnya sumber paling umum TDS yang ada diperairan berasal dari limpahan dari pertanian, limbah rumah tangga, dan industri. Dengan bercampurnya TDS dan limbah cair akan memunculkan perubahan salinitas, perubahan komposisi ion-ion, dan toksisitas masing-masing ion. Dimana Perubahan salinitas ini dapat menganggu keseimbangan biota air, biodiversitas, menimbulkan spesies yang kurang toleran, dan menyebabkan toksisitas yang tinggi pada tahapan hidup suatu organisme. Hal ini juga diungkapkan oleh. ${ }^{(11)}$ yang menyatakan bahwa Limbah cair yang berasal dari pencucian pada dasarnya mengandung padatan tersuspensi (TSS) yang kasar dan halus serta mengandung senyawa organik. Hal ini tetntu saja jika terjadi penimbunan secara berkelanjutan maka akan menimbulkan bau dan merusak lingkungan sekitar.

Dari tabel diatas juga menunjukkan bahwa TDS dan TSS setelah dilakukan perlakuan dengan elektrokoagulasi menurun drastis ke angka TDS 749 $\mathrm{mg} / \mathrm{l}$ dan TSS $505 \mathrm{mg} / \mathrm{l}$. dari pengamatan secara visual pada saat proses elektrokoagulasi berlangsung kekeruhan seiring dengan lama elektrokoagulasi akan menjadi berkurang hal ini terjadi karena seiring lamanya proses elektrokoagulasi maka kotoran akan teriku Bersama gelembung udara yang dihasilkan pada saat ion anoda dan ion katoda bertemu dan berbenturan sehingga akan mengikat partikel padatan terlarut maupun tersuspensi dengan cir terbentuknya buih cokelat kehitaman. Hal ini disebabkan oleh Proses elektrokoagulasi proses ekualisasi, proses elektrokimia (flokulasi-koagulasi) dan proses pengendapan yang terjadi pada elektrokoagulasi. Proses ekualisasi pada dasarnya bertujuan untu menghomogenkan limbah cair yang akan diolah terutama kondisi $\mathrm{pH}$, pada tahap ini tidak terjadi reaksi kimia. Pada proses elektrokimia akan terjadi pelepasan $\mathrm{Al} 3+$ dari plat elektrode (anoda) sehingga membentuk flok $\mathrm{Al}(\mathrm{OH}) 3$ yang mampu mengikat 
kontaminan dan partikel-partikel dalam limbah. ${ }^{(12)}$ Hal ini juga sejalan dengan penelitian yang dilakukan. (13) yang menyatakan bahwa pada hasil tiga kali percobaan elektrokoagulasi terhadap air sungai dan air waduk untuk nilai TDS pada air hasil elektrokoagulasi mengalami penurunan pada setiap percobaan, terutama pada tegangan listrik DC sebesar 25 volt dan waktu 1 jam. Berdasarkan data hasil elektrokoagulasi dapat diketahui bahwa proses elektrolisa atau elektrokoagulasi dapat menurunkan total dissolved solid (TDS) dengan besaran yang berbeda-beda. ${ }^{(13)}$ Hal yang sama dinyatakan oleh. ${ }^{(14)}$ yang mengatakan bahwa hasil terbaik diperoleh pada tegangan 5 volt untuk penghilangan COD $81,32 \%$ dengan nilai 233,5 mg / 1 pada waktu pemrosesan 180 menit, ini menunjukkan bahwa limbah yang diolah telah memenuhi standar kualitas untuk COD limbah pabrik adalah $350 \mathrm{mg} / 1$. Persentase pemindahan kekeruhan tertinggi diperoleh pada tegangan 5 volt dan pada waktu 180 menit dengan perolehan $95,08 \%$.

Penelitian yang dilakukan oleh. ${ }^{(15)}$ menyatakan bahwa dalam proses elektrokoagulasi dapat menghasilkan efisiensi penghilangan polutan yang optimum dalam kisaran waktu $40-180$ menit. Arus listrik dilakukan pada $0,5-5$ A dan tegangan yang digunakan sekitar $2-24$ volt. Meskipun proses elektrokoagulasi di kebanyakan penelitian, berbagai nilai $\mathrm{pH}$ tampaknya berfungsi dengan baik, tetapi $\mathrm{pH}$ optimum terjadi dalam kisaran $\mathrm{pH}$ kecil. Kisaran $\mathrm{pH}$ ini sebagian besar ditemukan dekat dengan nilai $\mathrm{pH}$ netral.

Berdasarkan hasil penelitian menunjukkan bahwa TDS dan TSS setelah dilakuan perlakuan dengan menggunakan prinsip destilasi menurun yaitu TDS $295 \mathrm{mg} / \mathrm{l}$ dan TSS $46 \mathrm{mg} / \mathrm{l}$. hal ini sesuai dengan penelitian yang dilakukan oleh. ${ }^{(16)}$ yang menyatakan bahwa Pada destilasi dengan suhu $105^{\circ} \mathrm{C}$ penurunan TDS terjadi seiring bertambahnya waktu dengan nilai awal TDS $226 \mathrm{mg} / \mathrm{L}$ menjadi $3 \mathrm{mg} / \mathrm{L}$ pada waktu destilasi 5 jam. Semakin tingi suhu maka akan semakin memperpendek waktu destilasi terhadap penurunan TDS seperti yang terjadi pada suhu $125^{\circ} \mathrm{C}$ dengan penurunan kadar TDS terjadi pada waktu 2 jam dan 3 jam, kadar akuades kembali meningkat pada waktu distilasi 4 jam dan pada waktu distilasi 5 jam kadar TDS kembali menurun daripada waktu distilasi 4 jam, namun kadar TDS terendah pada suhu $125^{\circ} \mathrm{C}$ terjadi pada waktu 3 jam dengan kadar TDS sebanyak $2 \mathrm{mg} / \mathrm{L}$. Pada suhu $145^{\circ} \mathrm{C}$ terjadi penurunan TDS yang awalnya $226 \mathrm{mg} / \mathrm{L}$ menjadi $6 \mathrm{mg} / \mathrm{L}$ pada waktu distilasi 2 jam, pada waktu distilasi 3 jam kadar TDS kembali meningkat menjadi $22 \mathrm{mg} / \mathrm{L}$, pada waktu distilasi 4 jam terjadi penurunan kembali kadar TDS menjadi $3 \mathrm{mg} / \mathrm{L}$ dan pada waktu distilasi 5 jam terjadi peningkatan kembali kadar akuades menjadi 23 $\mathrm{mg} / \mathrm{L}$. Hal ini juga didukung oleh penelitian yang dilakukan oleh. ${ }^{(17)}$ yang menyatakan bahwa Dari pengujian dan analisa data yang telah dilakukan, pada interval irradiasi matahari 304,4 - 574,4 watt $/ \mathrm{m} 2$, telah didapatkan perhitungan nilai effisiensi sistem sebesar $6 \%$ - 8,2\% dengan penurunan kadar garam selama proses distilasi pada sistem yang dibuat adalah sebesar 96,42\%. Hal ini dapat terjadi dikarenakan uap yang berubah menjadi cairan tidak membawa partikel padatan yang ada pada air limbah sebelum dilakukan destilasi. Keseluruhan unit destilator akan memishkan cairan dan padatan yang terlarut maupun yang terendapkan berdasarkan prinsip massa jenis suatu benda sehingga massa jenis benda yang berat tidak dapat dikonversi menjadi uap.(18) Penelitian (19), mengatakan bahwa yang sangat mempengaruhi efiesnsi dari destilasi adalah besarnya koefisien perpindahan panas menyeluruh.

Dari hasil penlitian menunjukkan bahwa perbandingan nilai TDS dan TSS pada limbah cair domestic di perumahan Tubo yang telah dilakukan perlakuan dan sebelum dilakukan perlakuan dengan menggunakan elektrokoagulasi menunjukkan bahwa terjadi penurunan significant yaitu TDS sebelum perlakuan sebesar $1614 \mathrm{mg} / \mathrm{l}$ setelah perlakuan turun menjadi $749 \mathrm{mg} / \mathrm{l}$. hal ini juga berlaku untuk nilai TSS dimana sebelum perlakuan nilai TSS sebesar 1995 setelah perlakuan menurun menjadi $505 \mathrm{mg} / \mathrm{l}$. hal ini sejalan dengan penelitian yang dilakukan oleh. (20) yang menyatakan bahwa elektrokoagulasi dengan kekuatan 18 volt dengan waktu 1 jam dapat menurunkan kadar TDS dan COD padan limbah aren dengan efisiensi penurunan masing-masing 85,74\% dan 58,6 \%. Pada prinsipnya elektrokoagulasi dapat menurunkan beban pencemar dikarenakan oleh terjadinya pelepasan koagulan alami secara elektrolisis yang ada pada elektroda dan pelelpasan dari elektroda juga akan berfungsi sebagai flokulan. Prinsip ini sama persis penambahan koagulan dengan menggunakan bahan kimia. Pada dasarnya aplikasi elektrokoagulasi adalah pasangan dua plat atau lebih yang akan dialir listrik sehingga plat tersebut berfungsi sebagai elektroda yang nantinya akan melepaskan ion ion yang berfungsi sebagai koagulan. Elektroda dapat berupa besi, baja, alumunium dan lain. ${ }^{(21)}$ Berdasarkan prinsip elektrokimia, anoda akan teroksidasi (kehilangan elektron), sedangkan pada katoda akan terjadi reduksi air. Jika digunakan elektroda aluminium (Al), pada anoda akan terjadi oksidasi Al, maka akan terbentuk koagulan berupa ion $\mathrm{Al}(\mathrm{H} 2 \mathrm{O}) 63+$, atau spesi aluminium yang lain. Pada elektrokoagulasi dengan menggunakan elektroda Aluminium akan terjadi reaksi sebagai berikut: Pada anoda: $\mathrm{Al}(\mathrm{s})$ ) $\rightarrow \mathrm{Al}(\mathrm{aq}) 3++3$ e- Pada katoda: $3 \mathrm{H} 2 \mathrm{O}+3 \mathrm{e}-\rightarrow 3 / 2 \mathrm{H} 2+3 \mathrm{OH}-$ Ion $\mathrm{Al} 3+$ selanjutnya mengalami hidrolisis membentuk $\mathrm{Al}(\mathrm{H} 2 \mathrm{O}) 63+$; $\mathrm{Al}(\mathrm{H} 2 \mathrm{O}) 5 \mathrm{OH} 2+; \quad \mathrm{Al} 2(\mathrm{OH}) 24+\quad ; \quad \mathrm{Al}(\mathrm{OH}) 4-$, Al6 $(\mathrm{OH}) 15$ 3+; , Al7 $(\mathrm{OH}) 17$ 4+ dan polialuminium ion lainnya. (22) Ion-ion inilah nantinya akan menetralkan dan mengikat polutan yang ada pada limbah cair dan membentuk flok. Flok yang terbentuk akan mengapng sehingga akan mengakibatkan air berubah menjadi kekuningan. Hal ini didukung oleh penelitian yang dilakukan oleh. ${ }^{(23)}$ yang menyatakan bahwa hasil elektrokoagulasi pada air sumur 
menunjukkan nilai kekeruhan berkurang drastis dibandingkan sebelum perlakuan dari 30 NTU menjadi $<1$ NTU, warna dari 125 TCU menjadi $<5$ TCU, konsentrasi logam Fe dari $2,51 \mathrm{mg} / 1$ menjadi $0,82 \mathrm{mg} / \mathrm{l}$, bakteri E. coli dari $80 \mathrm{APM} / 100 \mathrm{ml}$ menjadi $55 \mathrm{APM} / 100 \mathrm{ml}$ dan bakteri Coliform dari 1600 APM/100 ml menjadi 1180 APM/100 ml. Sedangkan pH dan suhu sudah berada pada kondisi netral dan normal sebesar 7,35 dan $30,3^{\circ} \mathrm{C}$, akan tetapi berbeda dengan logam Al yang mengalami kenaikan dari $0,034 \mathrm{mg} / \mathrm{l}$ menjadi $0,065 \mathrm{mg} / \mathrm{l}$.

Berdasarkan tori yang dikemukakan oleh. (24) menunjukkan bahwa Jumlah reaksi kimia untuk menghasilkan koagulan tergantung kepada jumlah listrik yang dialirkan, sebagaimana dirumuskan oleh hukum Faraday. Jumlah listrik yang dialirkan antara dua elektroda, tergantung kepada kuat arus yang mengalir dan lama waktu arus mengalir. Kuat arus yang dapat dialirkan sangat tergantung kepada daya hantar listrik larutan, serta tegangan listrik yang diterapkan. Dengan demikian air limbah yang berbeda akan memiliki sifat hantaran listrik yang berbeda, dan oleh karenanya memerlukan penerapan tegangan listrik yang berbeda untuk dapat mengalirkan listrik yang sama.

\section{SIMPULAN}

TDS pada perlakuan destilasi menurun sebesar $81,73 \% \quad(295 \mathrm{mg} / \mathrm{l})$ sedangkan TDS pada elektrokoagulasi menurun sebesar 53,60 \% (749 mg/ 1) dari angka sebelum perlakuan sebesar $1614 \mathrm{mg} / \mathrm{l}$ $(100 \%)$ dan TSS pada destilasi menurun sebesar $97,7 \% \quad(46 \mathrm{mg} / \mathrm{l})$ dibandingkan TSS pada elektrokoagulasi menurun sebesar 74,69\%(505 mg/l) dari angka sebelumnya $1995 \mathrm{mg} / 1$ (100\%). Perlakuan dengan menggunakan destilasi lebih efektif dalam menurunkan kadar TDS dan TSS pada limbah cair domestic.

\section{DAFTAR PUSTAKA}

1. Wirawan WA, Wirosoedarmo R, Susanawati LD. Pengolahan Limbah Cair Domestik Menggunakantanaman Kayu Apu (Pistia Stratiotes L.) Dengan Teknik Tanam Hidroponik Sistem Dft (Deepflowtechnique). Sumberd Alam Dan Lingkung. 2014;1(2):63-70.

2. Asmadi, Suharno. Dasar - Dasar Teknologi Pengolahan Air Limbah. Yogyakarta: Gosyen Publishing; 2012.

3. Rahmadi T. Mediasi Penyelesaian Sengketa Melalui Pendekatan Mufakat. Rajawali Pers. Jakarta: Rajawali Pers; 2011.

4. Pokja Sanitasi Kota Ternate. Laporan Studi Ehra. Ppsp; 2014. 1-33 Hal.

5. Pokja Sanitasi Kota Ternate. Memorandum Program Sanitasi (Mps) Kota Ternate. 1 Ed. Ppsp; 2015. 84 Hal.

6. BPS Kota Ternate. Kota Ternate Dalam Angka. Badan Pusat Statistik Kota Ternate. BPS Kota Ternate; 2018. 1-315 Hal.
7. Wardhani E, Dirgawati M, Valyana KP. Penerapan Metode Elektrokoagulasi Dalam Pengolahan Air Limbah Industri Penyamakan Kulit. In: Sudjono P, Darmanto, Sunjoto, Editor. Seminar Ilmiah Nasional, Penelitian Masalah Lingkungan di Indonesia 8. Ikatan Ahli Teknik Penyehatan Dan Lingkungan Indonesia; 2012. Hal. 1-16.

8. Prabowo A. Pengolahan Limbah Cair Yang Mengandung Minyak Dengan Proses Elektrokoagulasi Dengan Elektroda Besi. J Teknol Kim Dan Ind. 2012;1(1):355.

9. Tambunan FS, Edisar M, Junadi M. Destilasi Air Laut Menggunakan Pemanas Matahari Dengan Reflektor Cermin Cekung. Jom Fmipa. 2015;2(1):116-22.

10. Rinawati, Hidayat D, Suprianto R, Dewi PS. Penentuan Kandungan Zat Padat (Total Dissolve Solid Dan Total Suspended Solid ) Di Perairan Teluk Lampung. Anal Environ Chem. 2016;1(01):36-45.

11. Agustira R, Lubis KS, Jamilah. Kajian Karakteristik Kimia Air, Fisika Air Dan Debit Sungai Pada Kawasan DAS Padang Akibat Pembuangan Limbah Tapioka. J Online Agroekoteknologi. 2013;1(3):615-25.

12. Hernaningsih T. Tinjauan Teknologi Pengolahan Air Limbah Industri Dengan Proses Elektrokoagulasi. J Rekayasa Lingkung. 2016;9(1):31-46.

13. Suparman, Rahman A, Purwoto H. Penggunaan Metode Elektrokoagulasi Sebagai Alternatif Pengolahan Air Bersih Tanpa Bahan Kimia. J Agroteknose. 2016; Vii(2):46-59.

14. Hanum F, Tambun R, Ritonga MY, Kasim WW. Aplikasi Elektrokoagulasi Dalam Pengolahan Limbah Cair Pabrik Kelapa Sawit. J Tek Kim Usu. 2015;4(4):13-7.

15. Hernaningsih T. Tinjauan Teknologi Pengolahan Air Limbah Industri Dengan Proses Elektrokoagulasi. Jrl. 2016;9(1):31-46.

16. Khotimah H, Anggraeni EW, Setianingsih A. Karakterisasi Hasil Pengolahan Air Menggunakan Alat Destilasi. J Chemurg. 2017;01(2):34-8.

17. Wijaya A. Rancang Bangun Sistem Distilasi Air Dalam Proses Pengolahan Air Bersih Dengan Menggunakan Fresnel Lens Solar Collector. Magister Sci. 2016;0(40):71-83.

18. Walangare KBA, Lumenta ASM, Wuwung JO, Sugiarso BA. Rancang Bangun Alat Konversi Air Laut Menjadi Air Minum Dengan Proses Destilasi Sederhana Menggunakan Pemanas Elektrik. E-Jurnal Tek Elektro Dan Komput. 2013;1-11.

19. Adani SI, Pujiastuti YA. Pengaruh Suhu Dan Waktu Operasi Pada Proses Destilasi Untuk Pengolahan Aquades Di Fakultas Teknik Universitas Mulawarman. J Chemurg. 2017;01(1):31-5. 
20. Sutanto, Iryani A, Sarahwati. Efisiensi Dan Efektifitas Serta Kinetika Elektrokoagulasi Pengolahan Limbah Sagu Aren. Ekologia. 2018;18(1):10-6.

21. Gameissa MW, Suprihatin, Indrasti NS. Pengolahan Tersier Limbah Cair Industri Pangan Dengan Teknik Elektrokoagulasi Menggunakan Elektroda Stainless Steel. E-Jurnal Agroindustri Indones. 2012;1(1):31-7.

22. Chaturvedi SI. Electrocoagulation: A Novel
Waste Water Treatment Method. Int J Mod Eng Res. 2013;3(1):93-100.

23. Masthura, Jumiati E. Peningkatan Kualitas Air Menggunakan Metode Elektrokoagulasi Dan Filter Karbon. Fisitek J Ilmu Fis Dan Teknol. 2017;1(2):1-6.

24. Bard AJ, Larry RF. Electro-Chemical Methods, Fundamental And Application. John Wiley. New York; 1980. 